\title{
Stent insertion for hilar cholangiocarcinoma: a meta-analysis of comparison between unilateral and bilateral stenting
}

\author{
Ying Wang, Pei-Pei Liu, Lu-Lu Yang \\ Department of Radiology, Xuzhou Central Hospital, Xuzhou, China
}

Gastroenterology Rev 2021; 16 (4): 383-389

DOI: https://doi.org/10.5114/pg.2021.105022

Key words: stent, hilar cholangiocarcinoma, unilateral, bilateral.

\begin{abstract}
Address for correspondence: Lu-Lu Yang MD, Department of Radiology, Xuzhou Central Hospital, Xuzhou, China,
\end{abstract} e-mail: yanglulu1987@yeah.net

\begin{abstract}
Introduction: Metal stenting can be used as a primary treatment option for alleviating malignant hilar biliary obstruction (MHBO) symptoms. Although many studies have focused on the topic of unilateral or bilateral stenting for MHBO, there is a clear need for a study comparing these two stenting types in patients with a single type of cancer.

Aim: This meta-analysis was conducted to evaluate the relative clinical efficacy of unilateral and bilateral metal stent insertion for hilar cholangiocarcinoma (HCCA).

Material and methods: The PubMed, Embase, and Cochrane Library databases were searched to identify all relevant studies. This meta-analysis was conducted using RevMan v5.3.

Results: We initially identified 154 studies, seven of which were included in the final meta-analysis. These studies contained 524 HCCA patients treated by either unilateral $(n=215)$ or bilateral $(n=309)$ stent insertion. No significant differences were observed between groups in rates of technical success $(\mathrm{OR}=0.93 ; 95 \% \mathrm{Cl}: 0.34-2.54, p=0.88)$, clinical success $(\mathrm{OR}=1.03$; $95 \% \mathrm{Cl}: 0.49-2.15, p=0.94)$, stent dysfunction $(\mathrm{OR}=1.47 ; 95 \% \mathrm{Cl}: 0.91-2.39, p=0.12)$, or survival $(\mathrm{HR}=0.85 ; 95 \% \mathrm{Cl}: 0.50-$ $1.42, p=0.53)$. However, the unilateral group exhibited significantly lower complication rates ( $\mathrm{OR}=0.34 ; 95 \% \mathrm{Cl}: 0.13-0.88$, $p=0.03)$. Significant heterogeneity was found in the endpoint of survival. Funnel plot analysis did not suggest any publication bias relating to the selected study endpoints.

Conclusions: Compared to bilateral metal stenting, unilateral metal stenting could provide a similar clinical efficacy for patients with HCCA with a lower complication rate.
\end{abstract}

\section{Introduction}

Malignant hilar biliary obstruction (MHBO) always arises as a consequence of malignant growths in the hilar hepatobiliary area [1-4]. At the time of diagnosis, MHBO patients are generally unable to undergo definite resection as the disease is often detected at an advanced stage when only palliative treatment is viable [1-4].

Metal stenting can be used as a primary treatment option for alleviating MHBO symptoms [1-6]. At present, although many studies have focused on the topic of unilateral or bilateral stenting for $\mathrm{MHBO}$, it remains unclear as to which technique is preferable for treating $\mathrm{MHBO}$ [5-17]. Although some meta-analyses indicated that bilateral metal stenting yielded a lower rate of stent dysfunction than did unilateral metal stenting in
MHBO patients [5, 9], there were many forms of bias, such as type of stents, stenting approaches, and disease types. To overcome these potential causes of bias, there is a clear need for a study comparing these two stenting types in patients with a single type of cancer.

\section{Aim}

We conducted a meta-analysis to compare the clinical efficacy of unilateral and bilateral metal stent insertion for patients affected by hilar cholangiocarcinoma (HCCA).

\section{Material and methods}

The Preferred Reporting Items for Systematic reviews and Meta-Analyses (PRISMA) statement guided 
the conceptualization and execution of this meta-analysis. This meta-analysis was registered at https://inplasy. com/ (Number: INPLASY202110051).

Relevant studies published in the PubMed, Embase, and the Cochrane Library databases until June 2020 were identified. The search strategy adopted used the following search query: (((unilateral[Title/Abstract]) AND bilateral[Title/Abstract])) AND stent[Title/ Abstract]) AND ((biliary obstruction[Title/Abstract]) OR cholangiocarcinoma[Title/Abstract]).

Included studies met the following criteria: (a) studies comparing outcomes for unilateral vs. bilateral stenting for the treatment of HCCA; and (b) English studies.

Studies were excluded if they met any of the following criteria: (a) non-comparative studies; (b) case reports; (c) animal studies; and (d) reviews.

\section{Data extraction}

Two investigators independently extracted data (authors, publication year, baseline patient characteristics, study design, and treatment information) from all studies. Any discrepancies found in the extracted data were resolved by the corresponding author.

\section{Quality assessment}

The 8-point Jadad composite scale was utilized to evaluate randomized controlled trial (RCT) quality [17].
All non-RCTs were evaluated with the 9-point Newcastle-Ottawa scale [18].

\section{Endpoints and definitions}

Analyzed endpoints included rates of technical success, clinical success, complications, stent dysfunction, and overall survival.

Technical success was defined by successful stent placement beyond the obstructed site such that contrast media could pass easily through the stent. Clinical success was defined by $a \geq 30 \%$ decrease in total bilirubin levels within 2 weeks after stenting or a $50 \%$ reduction within 4 weeks [13-16]. Stent dysfunction was anything that resulted in reobstruction or stent migration [13-16]. Overall survival (OS) was defined as the time from stent implantation to death.

\section{Statistical analysis}

RevMan v5.3 was used for all data analyses. The Mantel-Haenszel approach was used for calculating pooled odds ratios (ORs) and 95\% confidence intervals (Cls) for dichotomous variables. Overall survival was assessed using hazard ratios (HRs) with 95\% Cls. Heterogeneity was measured using the $X^{2}$ and $l^{2}$ tests, with $I^{2}>50 \%$ indicating significant heterogeneity. When significant heterogeneity was not present, analysis was performed using a fixed-effects model. Potential heterogeneity sources were evaluated using sensitivity and

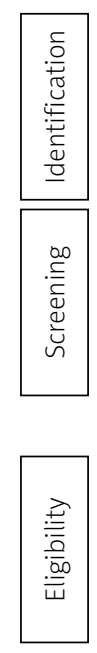

Records identified through database searching $(n=153)$

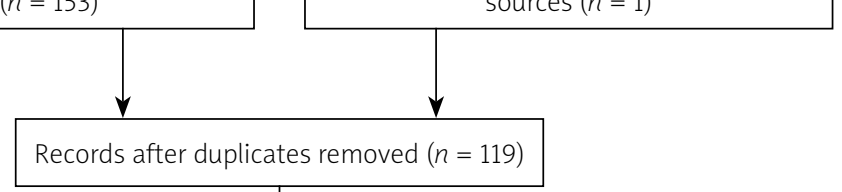

Additional records identified through other sources $(n=1)$

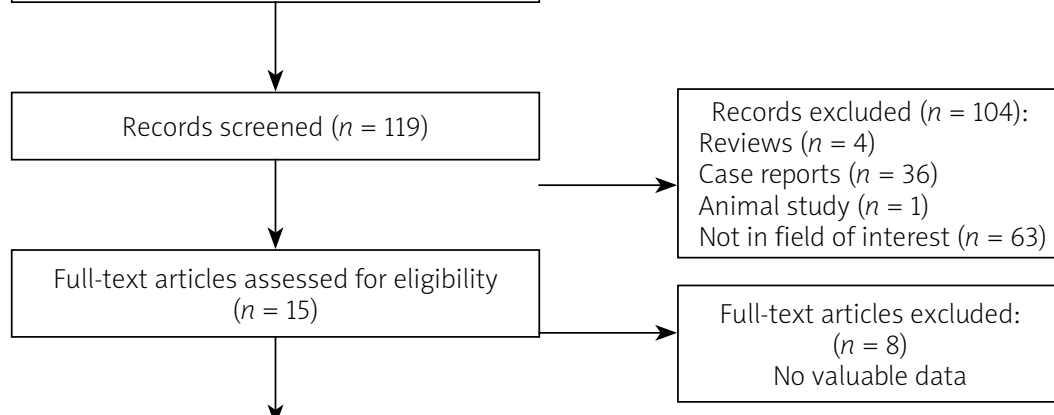

Studies included in qualitative synthesis $(n=7)$
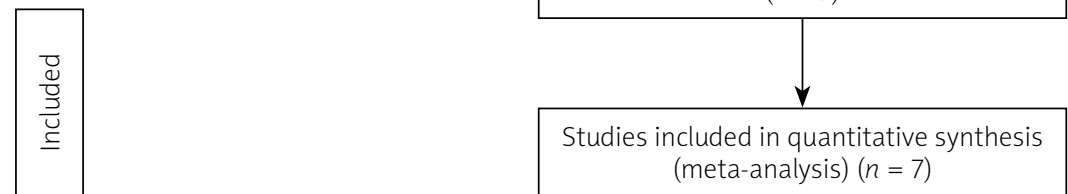

Figure 1. Flowchart of this meta-analysis 
subgroup analyses, while funnel plots were used to assess potential publication bias.

\section{Results}

\section{Study characteristics}

We initially identified 154 studies, seven of which were included in this meta-analysis (Figure 1). Six were retrospective studies [11-15, 17], while one was an RCT [16]. In total, these studies included 524 HCCA patients treated by either unilateral $(n=215)$ or bilateral $(n=$ 309) stenting.

Table I. Characteristics of the included studies

\begin{tabular}{|c|c|c|c|c|c|c|c|}
\hline Study/year/country & Study design & Bismuth & Groups & Sample size & Age [years] & Jadad scale & NOS \\
\hline \multirow[t]{2}{*}{ Naitoh/2009/Japan [11] } & \multirow[t]{2}{*}{ Retrospective } & \multirow[t]{2}{*}{ I-IV } & Unilateral & 6 & - & \multirow[t]{2}{*}{-} & \multirow[t]{2}{*}{5} \\
\hline & & & Bilateral & 9 & - & & \\
\hline \multirow[t]{2}{*}{ Liberato/2012/Portugal [12] } & \multirow[t]{2}{*}{ Retrospective } & \multirow[t]{2}{*}{ ॥ } & Unilateral & 35 & - & \multirow[t]{2}{*}{-} & \multirow[t]{2}{*}{6} \\
\hline & & & Bilateral & 42 & - & & \\
\hline \multirow[t]{2}{*}{ Chang/2017/China [13] } & \multirow[t]{2}{*}{ Retrospective } & \multirow[t]{2}{*}{ II-IV } & Unilateral & 23 & 63.3 & \multirow[t]{2}{*}{-} & \multirow[t]{2}{*}{8} \\
\hline & & & Bilateral & 23 & 68.5 & & \\
\hline \multirow[t]{2}{*}{ Yin/2019/China [14] } & \multirow[t]{2}{*}{ Retrospective } & \multirow[t]{2}{*}{ II-IV } & Unilateral & 51 & 64.3 & \multirow[t]{2}{*}{-} & \multirow[t]{2}{*}{8} \\
\hline & & & Bilateral & 42 & 68.5 & & \\
\hline \multirow[t]{2}{*}{ Teng/2019/China [15] } & \multirow[t]{2}{*}{ Retrospective } & \multirow[t]{2}{*}{ II-IV } & Unilateral & 33 & - & \multirow[t]{2}{*}{-} & \multirow[t]{2}{*}{5} \\
\hline & & & Bilateral & 35 & - & & \\
\hline \multirow[t]{2}{*}{ Fu/2019/China [16] } & \multirow[t]{2}{*}{$\mathrm{RCT}$} & \multirow[t]{2}{*}{ II-IV } & Unilateral & 17 & 65.2 & \multirow[t]{2}{*}{5} & \multirow[t]{2}{*}{-} \\
\hline & & & Bilateral & 21 & 64.3 & & \\
\hline \multirow[t]{2}{*}{ Staub/2020/Multicenter [17] } & \multirow[t]{2}{*}{ Retrospective } & \multirow[t]{2}{*}{ I-IV } & Unilateral & 50 & 73.1 & \multirow[t]{2}{*}{-} & \multirow[t]{2}{*}{7} \\
\hline & & & Bilateral & 137 & 72.1 & & \\
\hline
\end{tabular}

NOS - Newcastle-Ottawa scale, RCT-randomized controlled trial.

Table II. Characteristics of treatments

\begin{tabular}{|c|c|c|c|c|c|c|c|}
\hline Study & Deployments & Approaches & Groups & TS & CS & SD & Complications \\
\hline \multirow[t]{2}{*}{ Naitoh [11] } & \multirow[t]{2}{*}{ Side-by-side } & \multirow[t]{2}{*}{ Endoscopic } & Unilateral & Not given & Not given & $3 / 6(50 \%)$ & Not given \\
\hline & & & Bilateral & Not given & Not given & $2 / 9(22.2 \%)$ & Not given \\
\hline \multirow[t]{2}{*}{ Liberato [12] } & \multirow{2}{*}{$\begin{array}{l}\text { Side-by-side, } \\
\text { stent-in-stent }\end{array}$} & \multirow[t]{2}{*}{ Endoscopic } & Unilateral & $35 / 35$ (100\%) & Not given & $11 / 35$ (31.4\%) & Not given \\
\hline & & & Bilateral & $42 / 45(93.3 \%)$ & Not given & $5 / 42(11.9 \%)$ & Not given \\
\hline \multirow[t]{2}{*}{ Chang [13] } & \multirow[t]{2}{*}{ Side-by-side } & \multirow[t]{2}{*}{ Percutaneous } & Unilateral & $22 / 23(95.7 \%)$ & $21 / 22(95.4 \%)$ & $2 / 22(9.1 \%)$ & $1 / 22(4.5 \%)$ \\
\hline & & & Bilateral & 23/23 (100\%) & 23/23 (100\%) & $1 / 23(4.3 \%)$ & 3/23 (13.0\%) \\
\hline \multirow[t]{2}{*}{ Yin [14] } & \multirow[t]{2}{*}{ Side-by-side } & \multirow[t]{2}{*}{ Percutaneous } & Unilateral & $47 / 51(92.2 \%)$ & $45 / 47$ (95.7\%) & $6 / 47(12.8 \%)$ & $3 / 47(6.4 \%)$ \\
\hline & & & Bilateral & $40 / 42(95.2 \%)$ & $38 / 39$ (97.4\%) & $3 / 40(7.5 \%)$ & $5 / 40(12.5 \%)$ \\
\hline \multirow[t]{2}{*}{ Teng [15] } & \multirow[t]{2}{*}{ Side-by-side } & \multirow[t]{2}{*}{ Percutaneous } & Unilateral & Not given & $32 / 33(97.0 \%)$ & Not given & Not given \\
\hline & & & Bilateral & Not given & $34 / 35$ (97.1\%) & Not given & Not given \\
\hline \multirow[t]{2}{*}{$\mathrm{Fu}[16]$} & \multirow[t]{2}{*}{ Side-by-side } & \multirow[t]{2}{*}{ Percutaneous } & Unilateral & $15 / 17(88.2 \%)$ & 14/15 (93.3\%) & 2/15 (13.3\%) & 2/15 (13.3\%) \\
\hline & & & Bilateral & $18 / 21(85.7 \%)$ & $18 / 18(100 \%)$ & $1 / 18(5.6 \%)$ & $1 / 18(5.6 \%)$ \\
\hline \multirow[t]{2}{*}{ Staub [17] } & \multirow[t]{2}{*}{ Not given } & \multirow[t]{2}{*}{ Endoscopic } & Unilateral & $50 / 50(100 \%)$ & Not given & $21 / 50(42 \%)$ & $0 / 50(0 \%)$ \\
\hline & & & Bilateral & $137 / 137$ (100\%) & Not given & 60/137 (43.8\%) & $16 / 137(11.7 \%)$ \\
\hline
\end{tabular}

TS - technical success, CS - clinical success, SD - stent dysfunction. related data were directly extracted from 5 studies $[11,12,14,15,17]$. Two studies did not directly report the data of HCCA patients, and we obtained the data by contacting the corresponding authors of these articles $[13,16]$. Endoscopic stenting was performed in three studies $[11,12,17]$, whereas percutaneous stenting was conducted in four studies [13-16]. The 6 retrospective studies were evaluated as Newcastle-Ottawa scale 5-8. The 1 RCT was evaluated as Jadad scale 5 .

Details of included studies are shown in Tables I 


\section{Technical success}

Technical success rates could be obtained from five studies [12-14, 16, 17]. No significant heterogeneity was detected $\left(I^{2}=0 \% ; p=0.52\right.$, Figure $\left.2 \mathrm{~A}\right)$. The pooled technical success rates of unilateral and bilateral stenting were $96 \%$ and $97 \%$, respectively $(\mathrm{OR}=0.93 ; 95 \% \mathrm{Cl}$ : $0.34-2.54, p=0.88)$.

\section{Clinical success}

Data regarding rates of clinical success could be obtained from five studies [13-17]. No significant heterogeneity was seen $\left(I^{2}=0 \% ; p=0.80\right.$, Figure $\left.2 \mathrm{~B}\right)$. The pooled rates of clinical success of unilateral and bilateral stenting were $92.8 \%$ and $89.7 \%$, respectively $(\mathrm{OR}=$ $1.03 ; 95 \% \mathrm{Cl}: 0.49-2.15, p=0.94)$.

\section{Complications}

Complication data could be obtained from four studies [13, 15-17]. No significant heterogeneity was seen $\left(I^{2}=22 \% ; p=0.28\right.$, Figure $\left.2 \mathrm{C}\right)$. The pooled rates of complication of unilateral and bilateral stenting were $4.5 \%$ and $11.5 \%$, respectively $(\mathrm{OR}=0.34$; $95 \% \mathrm{Cl}: 0.13-$ $0.88, p=0.03)$.

\section{Stent dysfunction}

Stent dysfunction rates were available from six studies $[11-14,16,17]$. No significant heterogeneity was detected $\left(I^{2}=0 \% ; p=0.44\right.$, Figure $\left.2 \mathrm{D}\right)$. The pooled rates of stent dysfunction of unilateral and bilateral stenting were $25.7 \%$ and $26.7 \%$, respectively $(\mathrm{OR}=1.47 ; 95 \% \mathrm{Cl}$ : $0.91-2.39, p=0.12)$.

A

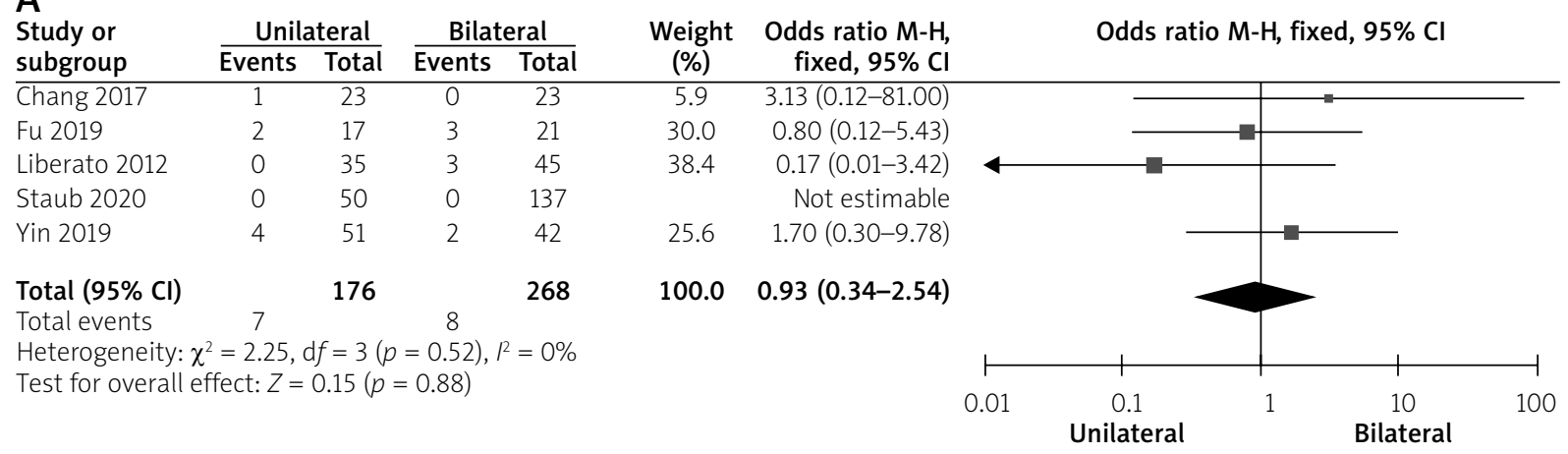

\section{B}

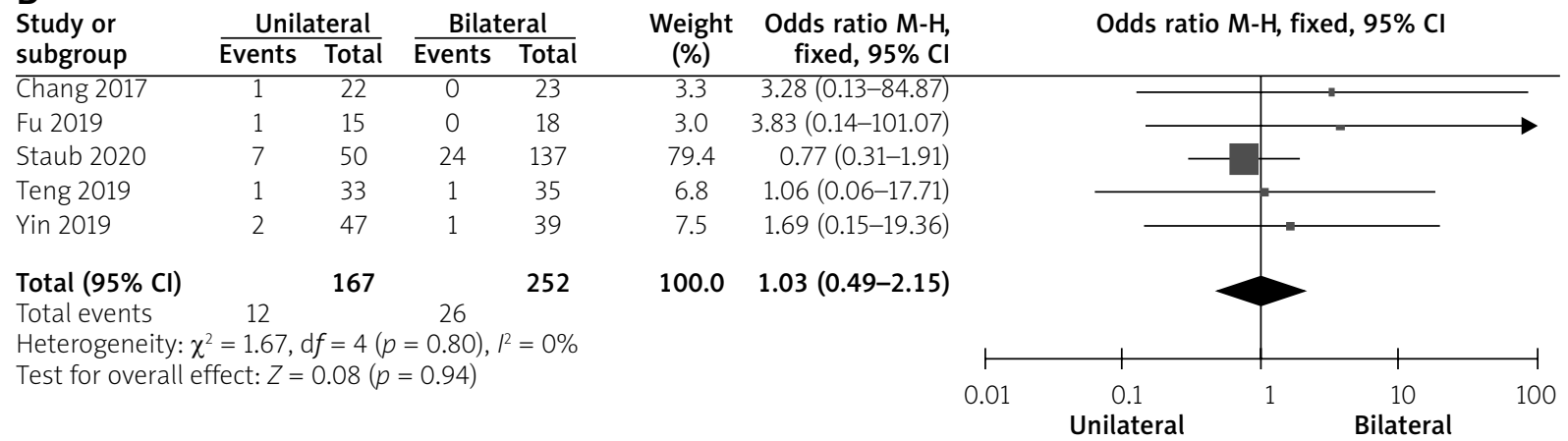

\section{C}

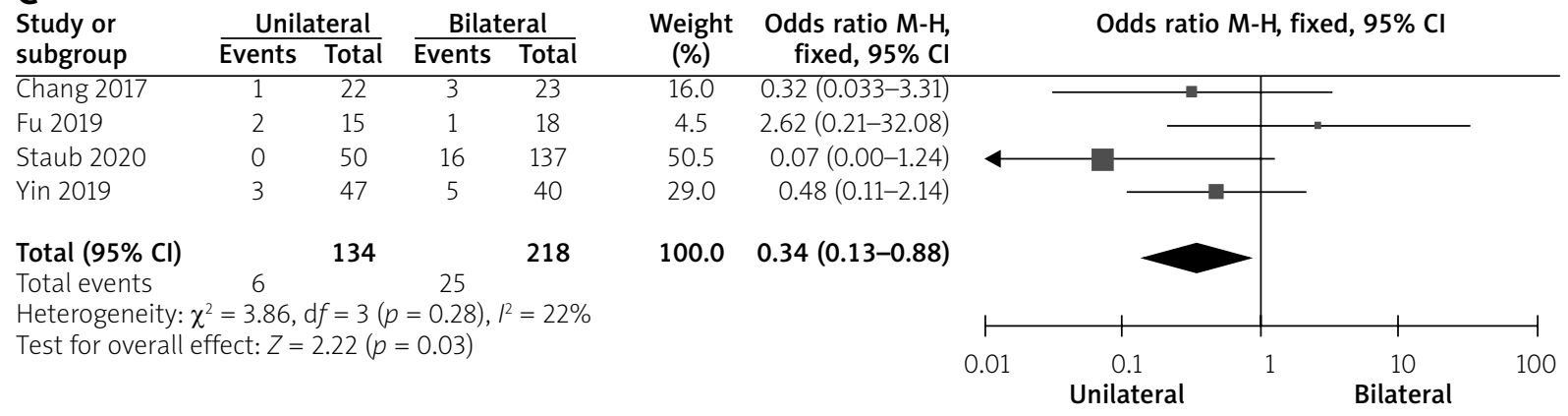

Figure 2. Forest plots showing the comparisons in technical success rates (A), clinical success rates (B), complication rates $(\mathbf{C})$ 


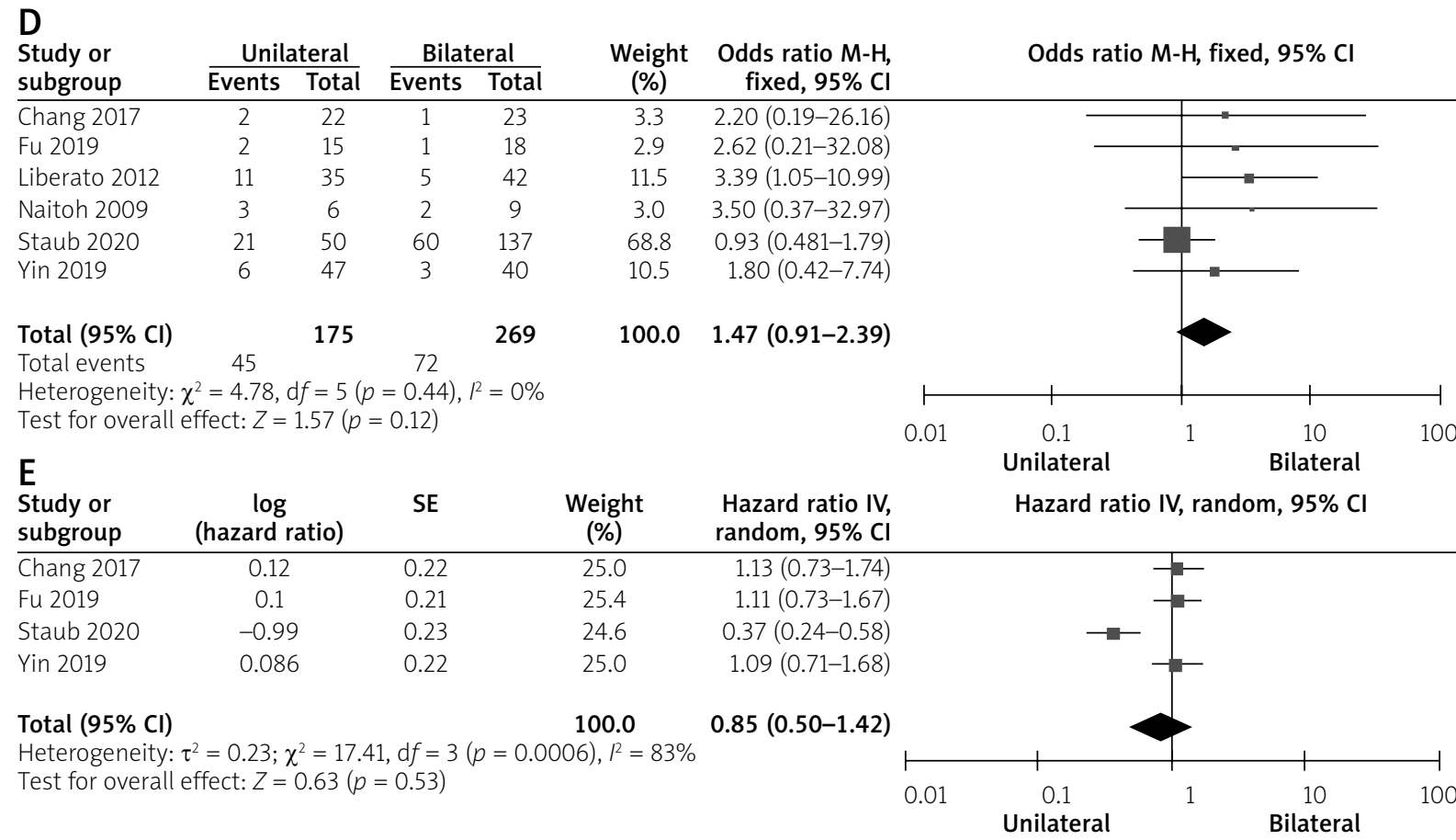

Figure 2. Cont. Stent dysfunction rates (D) and overall survival between 2 groups (E)

\section{Overall survival}

Overall survival could be extracted from four studies $[13,14,16,17]$. Significant heterogeneity was detected $\left(I^{2}=83 \% ; p=0.0006\right.$, Figure $\left.2 \mathrm{E}\right)$. Overall survival did not differ significantly between the 2 groups $(\mathrm{HR}=0.85$; $95 \% \mathrm{Cl}: 0.50-1.42, p=0.53)$. The sensitivity analysis revealed that the source of heterogeneity was the Staub study [17].

\section{Subgroup analysis}

Table III shows the pooled stent dysfunction rates based on the use of endoscopic or percutaneous stenting. Significant heterogeneity was detected in the subgroup of endoscopic stenting $\left(1^{2}=54 \%\right)$. The difference between the 2 groups based on the 2 subgroups was not significant.

\section{Publication bias}

Funnel plot analysis did not suggest any publication bias relating to the selected study endpoints.

\section{Discussion}

HCCA is the most common cause of MHBO [11-17]. Metal stents currently represent a standard treatment for $\mathrm{MHBO}$, as they offer greater advantages in terms of clinical success, stent patency, and patient survival than do plastic stents [10]. However, it has remained controversial as to whether MHBO or HCCA is best managed via unilateral or bilateral stenting.

Unlike previous meta-analyses regarding unilateral vs. bilateral stenting for $\operatorname{MHBO}[5,9,19,20]$, this meta-analysis solely focused on HCCA. We observe no significant differences in either technical $(p=0.52)$ or clinical ( $p=0.80)$ success when comparing patients treated via unilateral and bilateral metal stenting, consistent with previous meta-analyses regarding treating $\mathrm{MHBO}$ via percutaneous or endoscopic stenting [5, 9]. Unilateral stent insertion is sufficient to relieve MHBO-associated jaundice, as TBIL levels can be normalized by facilitating the drainage of just $25-30 \%$ of the liver [12].

Table III. Meta-analytic pooled stent dysfunction rates based on the subgroup analysis

\begin{tabular}{lcccc} 
Variable & Number of studies & OR $(95 \% \mathrm{Cl})$ & Favorable & Heterogeneity \\
\hline Total & 6 & $1.46(0.89,2.40), p=0.14$ & $R^{2}=0 \%$ \\
\hline Stenting approaches: & 3 & & - & $P^{2}=0 \%$ \\
\hline \multicolumn{1}{c}{ Percutaneous } & 3 & $1.78(0.64,4.92), p=0.27$ & -
\end{tabular}


A meta-analysis regarding of endoscopic unilateral vs. bilateral metal stenting for $\mathrm{MHBO}$ indicated a significant higher technical success rate in the unilateral group [20]. In our meta-analysis, four studies used percutaneous stenting [13-16]. Compared to the endoscopic approach, percutaneous stenting for $\mathrm{MHBO}$ is easier, as the distance from puncture site to obstructed site is very short.

In this meta-analysis, we found a significantly higher complication rate in the bilateral group (11.5\% vs. $4.5 \%$, $p=0.03)$. Six included studies reported the use of sideby-side technique of bilateral stenting, which necessitates the insertion of two stents into the common biliary tract. This can induce higher levels of compressive stress on the biliary wall, thereby potentially increasing the risk of cholangitis.

A significant lower bilateral stent dysfunction rate was found in the previous studies regarding unilateral vs. bilateral stenting for MHBO [5, 9]. However, our meta-analysis demonstrated similar stent dysfunction rates between 2 groups ( $25.7 \%$ vs. $26.7 \%, p=0.12)$. This finding may be related to the following factors: (a) the HCCA is a subtype of $\mathrm{MHBO}$, therefore, the sample size decreases; and (b) six of the 7 included studies were retrospective in design and may thus be affected by selection bias. The subgroup analysis still revealed similar stent dysfunction rates between the 2 groups based on the percutaneous or endoscopic approaches. Further high quality studies are still required to confirm this finding.

We observed similar OS between the 2 groups $(p=0.53)$, which may be because some of the patients included in the present meta-analysis were from studies in which stenting was employed as a post-operative anti-cancer treatment $[13,14,16]$. While such stenting can relieve jaundice in HCCA patients, it cannot directly impact the primary malignancy. Instead, further anti-cancer treatments are necessary to extend patient survival in these cases [21].

There are a number of limitations to the present meta-analysis. First, the majority of the studies included herein were retrospective in nature, thus introducing the potential for selection bias. Second, the studies included in the present meta-analysis used a number of different stent insertion approaches, including percutaneous and endoscopic approaches, thus potentially further biasing these results. Third, many endpoint data were lost in many included studies, thus potentially constraining the applicability of our findings.

\section{Conclusions}

Compared to bilateral metal stenting, unilateral metal stenting could provide similar clinical efficacy for patients with HCCA with a lower complication rate.

\section{Acknowledgments}

Program of 2019 Xuzhou clinical technique research (2109GG002).

\section{Conflict of interest}

The authors declare no conflict of interest.

\section{References}

1. Naitoh I, Hayashi K, Nakazawa T, et al. Side-by-side versus stent-in-stent deployment in bilateral endoscopic metal stenting for malignant hilar biliary obstruction. Dig Dis Sci 2012; 57: 3279-85.

2. Li M, Bai M, Qi X, et al. Percutaneous transhepatic biliary metal stent for malignant hilar obstruction: results and predictive factors for efficacy in 159 patients from a single center. Cardiovasc Intervent Radiol 2015; 38: 709-21.

3. Li M, Li K, Qi X, et al. Percutaneous transhepatic biliary stent implantation for obstructive jaundice of perihilar cholangiocarcinoma: a prospective study on predictors of stent patency and survival in 92 patients. J Vasc Interv Radiol 2016; 27 : 1047-55.e2.

4. Law R, Baron TH. Bilateral metal stents for hilar biliary obstruction using a 6Fr delivery system: outcomes following bilateral and side-by-side stent deployment. Dig Dis Sci 2013; 58: 2667-72.

5. Ashat M, Arora S, Klair JS, et al. Bilateral vs unilateral placement of metal stents for inoperable high grade hilar biliary strictures: a systemic review and meta-analysis. World J Gastroenterol 2019; 25: 5210-9.

6. Lee TH, Kim TH, Moon JH, et al. Bilateral versus unilateral placement of metal stents for inoperable high-grade malignant hilar biliary strictures: a multicenter, prospective, randomized study (with video). Gastrointest Endosc 2017; 86: 817-27.

7. Jang SI, Lee DK. Update on pancreatobiliary stents: stent placement in advanced hilar tumors. Clin Endosc 2015; 48: 201-8.

8. Sangchan A, Kongkasame W, Pugkhem A, et al. Efficacy of metal and plastic stents in unresectable complex hilar cholangiocarcinoma: a randomized controlled trial. Gastrointest Endosc 2012; 76: 93-9.

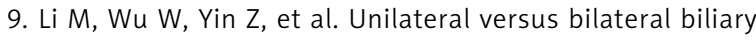
drainage for malignant hilar obstruction: a systematic review and meta-analysis. Zhonghua Gan Zang Bing Za Zhi 2015; 23 : 118-23.

10. Perdue DG, Freeman ML, DiSario JA, et al. Plastic versus self-expanding metallic stents for malignant hilar biliary obstruction: a prospective multicenter observational cohort study. J Clin Gastroenterol 2008; 42: 1040-6.

11. Naitoh I, Ohara H, Nakazawa T, et al. Unilateral versus bilateral endoscopic metal stenting for malignant hilar biliary obstruction. J Gastroenterol Hepatol 2009; 24: 552-7.

12. Liberato MJ, Canena JM. Endoscopic stenting for hilar cholangiocarcinoma: efficacy of unilateral and bilateral placement of plastic and metal stents in a retrospective review of 480 patients. BMC Gastroenterol 2012; 12: 103.

13. Chang G, Xia FF, Li HF, et al. Unilateral versus bilateral stent insertion for malignant hilar biliary obstruction. Abdom Radiol (NY) 2017; 42: 2745-2751. 
14. Yin X, Li DM, Yang F, et al. Self-expanded metallic stent insertion for hilar cholangiocarcinoma: comparison of unilateral and bilateral stenting. J Laparoendosc Adv Surg Tech A 2019; 29: 1501-6.

15. Teng F, Xian YT, Lin J, et al. Comparison of unilateral with bilateral metal stenting for malignant hilar biliary obstruction. Surg Laparosc Endosc Percutan Tech 2019; 29: 43-8.

16. Fu YF, Zhou WJ, Shi YB, et al. Percutaneous stenting for malignant hilar biliary obstruction: a randomized controlled trial of unilateral versus bilateral stenting. Abdom Radiol 2019; 44: 2900-8.

17. Staub J, Siddiqui A, Murphy $M$, et al. Unilateral versus bilateral hilar stents for the treatment of cholangiocarcinoma: a multicenter international study. Ann Gastroenterol 2020; 33: 202-9.

18. Jadad AR, Moore RA, Carroll D, et al. Assessing the quality of reports of randomized clinical trials: is blinding necessary? Control Clin Trials 1996; 17: 1-12.

19. Lo CK, Mertz D, Loeb M. Newcastle-Ottawa Scale: comparing reviewers' to authors' assessments. BMC Med Res Methodol 2014; 14: 45.

20. Aghaie Meybodi M, Shakoor D, Nanavati J, et al. Unilateral versus bilateral endoscopic stenting in patients with unresectable malignant hilar obstruction: a systematic review and meta-analysis. Endosc Int Open 2020; 8: E281-90.

21. Li TF, Chen C, Han XW, et al. Clinical efficacy of metallic biliary stents combined with different anti-cancer treatments in the management of bile duct cancer. Hepatogastroenterology 2014; 61: 22-6.

Received: 3.02 .2021

Accepted: 23.02 .2021 